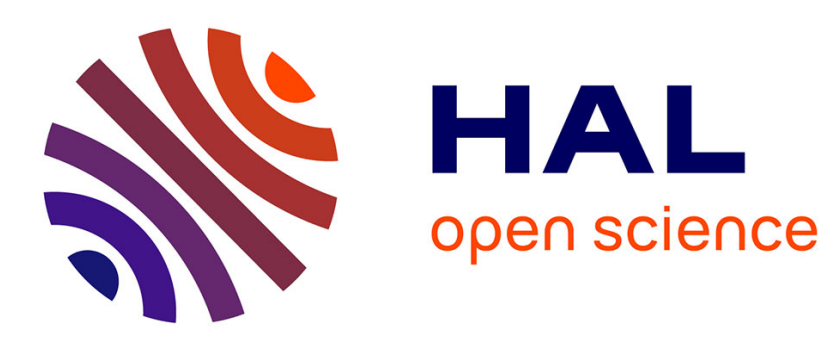

\title{
A new approach for assessing the clear-sky direct normal irradiance in real time
}

Rémi Chauvin, Julien Nou, Stéphane Thil, Stéphane Grieu

\section{To cite this version:}

Rémi Chauvin, Julien Nou, Stéphane Thil, Stéphane Grieu. A new approach for assessing the clear-sky direct normal irradiance in real time. 17th International Conference on Environment and Electrical Engineering (IEEE EEEIC), Jun 2016, Florence, Italy. hal-01364269

\section{HAL Id: hal-01364269 \\ https://hal.science/hal-01364269}

Submitted on 15 Sep 2016

HAL is a multi-disciplinary open access archive for the deposit and dissemination of scientific research documents, whether they are published or not. The documents may come from teaching and research institutions in France or abroad, or from public or private research centers.
L'archive ouverte pluridisciplinaire HAL, est destinée au dépôt et à la diffusion de documents scientifiques de niveau recherche, publiés ou non, émanant des établissements d'enseignement et de recherche français ou étrangers, des laboratoires publics ou privés. 


\title{
A new approach for assessing the clear-sky direct normal irradiance in real time
}

\author{
Rémi Chauvin, Julien Nou, Stéphane Thil and Stéphane Grieu \\ PROMES-CNRS (UPR 8521) \\ University of Perpignan Via Domitia \\ Perpignan, France \\ remi.chauvin@promes.cnrs.fr, julien.nou@promes.cnrs.fr, stephane.thil@promes.cnrs.fr, stephane.grieu@promes.cnrs.fr
}

\begin{abstract}
In the present paper, a new approach is proposed to assess the clear-sky direct normal irradiance (DNI) in real time. This approach combines an existing empirical model, proposed by Ineichen and Perez in 2002, with a new methodology for the computation of atmospheric turbidity. This methodology takes advantage of the fact that changes in atmospheric turbidity are relatively small throughout the day in comparison to changes in DNI, even when the sky is free of clouds. We considered data from two experimental sites (Golden, in the USA, and Perpignan, in France) and compared the proposed approach with several combinations of empirical models and ways of computing atmospheric turbidity. A polynomial of the cosine of the solar zenith angle has also been included in the comparative study. In both sites, our approach outperforms the other approaches. It has proven to be well adapted to the real-time assessment of the clear-sky DNI, in particular when the Sun is occulted by clouds during less than eight consecutive hours.
\end{abstract}

\section{INTRODUCTION}

In a context of sustainable development, solar technologies like concentrating solar power (CSP) are becoming an important source of renewable energy in countries like Spain and USA and can potentially be used at a very large scale in many other countries. One of the most challenging topics is to improve the solar resource assessment and forecasting in order to optimize the operational strategies of the plants. In CSP plants, electricity generation is directly impacted by the availability and variability of the solar resource and, more specifically, by direct normal irradiance (DNI). In addition, having access to forecasted values of DNI could contribute to lower the cost related to grid integration. DNI can be defined as the direct irradiance received on a plane normal to the Sun [1] and can be split into two multiplicative terms (Eq. (1)):

$$
I=I_{c s} \cdot k_{c}
$$

where $I_{c s}$ is the clear-sky DNI and $k_{c}$ is the clearness index. Regarding the clear-sky DNI, on which the present paper focuses, models are divided into two categories: radiative transfer models and empirical models [2]-[4]. In radiative transfer models, the clear-sky DNI is usually derived from the Beer-Lambert law (Eq. (2)):

$$
I_{c s}=I_{0} \cdot e^{-m \tau}
$$

where $I_{0}$ is the extraterrestrial solar irradiance, $m$ is the relative optical air mass and $\tau$ is the optical depth of the atmosphere. Although radiative transfer models often produce better estimates of the clear-sky DNI than empirical models, they need input data that might be not available at any time. As a result, radiative transfer models are not suitable for realtime applications. Regarding empirical models, several levels of complexity can be distinguished. One can first mention an eight-order polynomial of the cosine of the solar zenith angle [5], [6]. These past few years, several studies have been dedicated to developing more efficient models [7]-[9]. Basically, they use atmospheric turbidity, which can be determined from broadband beam radiation measurements, as an additional input [10]. However, in these models, information about the state of the atmosphere is not available in real time and is generally derived from mean values or approximations provided by solar energy services like the SoDa service [11]. Because atmospheric turbidity can be quite variable over the days, accuracy of the models can be unsatisfactory, especially for high solar zenith angles.

The main purpose of the present paper is to propose a new and efficient approach to assess in real time the clear-sky DNI. This approach combines an existing empirical model with a new methodology for the computation of atmospheric turbidity. This methodology relies on a persistence of atmospheric turbidity at short notice and takes advantage of the fact that changes in this quantity are relatively small throughout the day in comparison to changes in DNI, even when the sky is free of clouds. So, atmospheric turbidity is computed using the last detected clear-sky DNI measurement. Data from two experimental sites (Golden, in the USA, and Perpignan, in France) have been used to compare the proposed approach with several combinations of empirical clear-sky DNI models and ways of computing atmospheric turbidity. The abovementioned polynomial of the cosine of the solar zenith angle has also been included in the comparative study.

\section{REAL-TIME ASSESSMENT OF THE CLEAR-SKY DNI}

In this section are presented the selected empirical models as well as the approaches included in the comparative study.

\section{A. Selected empirical models}

Three empirical clear-sky DNI models have been selected. The first one is the polynomial of the cosine of the solar zenith 
TABLE I

APPROACHES INCLUDED IN THE COMPARATIVE STUDY.

\begin{tabular}{lccc}
\hline Model & $\begin{array}{c}\text { Computation } \\
\text { of } T_{L I}\end{array}$ & $\begin{array}{c}\text { Name of the } \\
\text { approach }\end{array}$ & $\begin{array}{c}\text { Clear-sky } \\
\text { DNI }\end{array}$ \\
\hline Polynomial of degree $N$ & - & $1, N$ & $\hat{I}_{c s 1, N}$ \\
\hline \multirow{3}{*}{ ESRA } & $\left\langle T_{L I}\right\rangle_{y}$ & 2,1 & $\hat{I}_{c s 2,1}$ \\
& $\left\langle T_{L I}\right\rangle_{m}$ & 2,2 & $\hat{I}_{c s 2,2}$ \\
& $\left\langle T_{L I}\right\rangle_{d}$ & 2,3 & $\hat{I}_{c s 2,3}$ \\
\hline \multirow{3}{*}{ Ineichen and Perez } & $\left\langle T_{L I}\right\rangle_{y}$ & 3,1 & $\hat{I}_{c s 3,1}$ \\
& $\left\langle T_{L I}\right\rangle_{m}$ & 3,2 & $\hat{I}_{c s 3,2}$ \\
& $\left\langle T_{L I}\right\rangle_{d}$ & 3,3 & $\hat{I}_{c s 3,3}$ \\
& $\left\langle T_{L I}\right\rangle_{d-1}$ & 3,4 & $\hat{I}_{c s 3,4}$ \\
& $T_{L I}\left(t^{\star}\right)$ & 3,5 & $\hat{I}_{c s 3,5}$
\end{tabular}

angle. It is defined in the following way (Eq. (3)):

$$
\hat{I}_{c s 1}=\sum_{n=0}^{N} a_{n} \cdot(\cos z)^{n}
$$

where $z$ is the solar zenith angle. The coefficients $\left\{a_{n}\right\}_{0 \leqslant n \leqslant N}$ can be obtained by using the least-squares method. The second model, developed by the ESRA, is given by Eq. (4):

$$
\hat{I}_{c s 2}=I_{0} \cdot \exp \left(-0.8662 m_{p} \cdot \delta_{c d a} \cdot T_{L I}\right)
$$

where $m_{p}$ is the relative optical air mass corrected by the altitude of the site, and $\delta_{c d a}$ is the optical thickness of a waterand aerosol-free atmosphere (a clean and dry atmosphere) and $T_{L I}$ is the atmospheric turbidity coefficient revised by Ineichen and Perez [10]. It can be easily obtained by using clear-sky DNI measurements (see Subsection IV-A for details). The third model, from Ineichen and Perez [10], is given by Eq. (5):

$$
\hat{I}_{c s 3}=b \cdot I_{0} \cdot \exp \left(-0.09 m \cdot\left(T_{L I}-1\right)\right)
$$

where $b$ is a function of the altitude of the considered site.

\section{B. Approaches included in the comparative study}

Table I summarizes all the approaches included in the comparative study. For the polynomial model given by Eq (3), we varied its degree from one to eight. Regarding the empirical models given by Eqs. (4) and (5), several inputs have been tested depending on the way atmospheric turbidity is computed. These inputs can be:

- the yearly $\left(\left\langle T_{L I}\right\rangle_{y}\right)$, monthly $\left(\left\langle T_{L I}\right\rangle_{m}\right)$ or daily $\left(\left\langle T_{L I}\right\rangle_{d}\right)$ mean value of atmospheric turbidity;

- the mean value of atmospheric turbidity during the previous day $\left(\left\langle T_{L I}\right\rangle_{d-1}\right)$;

- the last trustable value of atmospheric turbidity $\left(T_{L I}\left(t^{\star}\right)\right)$. See Section IV-A for an overview of the methodology proposed for the computation of this value.

\section{EXPERIMENTAL DATA}

To evaluate the accuracy of these approaches, we used one year of data from two experimental sites. The first database comes from the Measurement and Instrumentation Data Center
(MIDC). The MIDC makes available irradiance and meteorological data from more than thirty stations in the United States. In the present study, we focused on data from the BMS (Baseline Measurement System) station which is located near Golden (Colorado), at the NREL (National Renewable Energy Laboratory) [12]. This station is situated on a high plain (altitude is about $1800 \mathrm{~m}$ ), near mountains reaching about $3000 \mathrm{~m}$ elevation.

TABLE II

CHARACTERISTICS OF THE TWO EXPERIMENTAL SITES

\begin{tabular}{lll}
\hline Characteristics & Golden, USA & Perpignan, France \\
\hline Laboratory & NREL & PROMES-CNRS \\
Time zone & GMT-7 & GMT+1 \\
GPS & $39.74 \mathrm{~N}, 105.18 \mathrm{~W}$ & $42.66 \mathrm{~N}, 2.91 \mathrm{E}$ \\
Altitude & $1829 \mathrm{~m}$ & $50 \mathrm{~m}$ \\
Period of acquisition & $01 / 01 / 13-31 / 12 / 13$ & $01 / 11 / 13-31 / 10 / 14$ \\
Time step & $60 \mathrm{~s}$ & $60 \mathrm{~s}$ \\
Device used for & Pyrheliometer & Rotating shadowband \\
DNI measurement & $\pm 2 \%$ & irradiometer \\
Typical uncertainty & $\pm 5 \%$ \\
Yearly turbidity & 2.37 & 2.61 \\
\hline
\end{tabular}

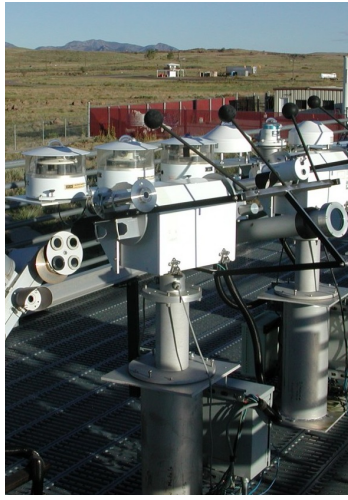

(a) Pyrheliometer (Golden, USA)

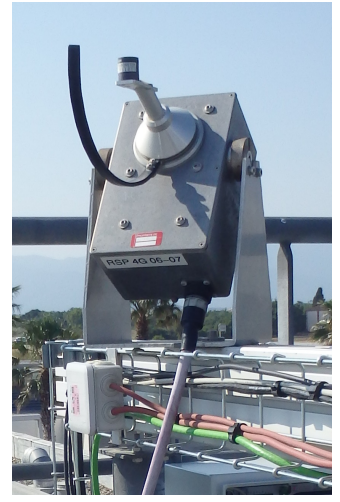

(b) RSI
Fig. 1. The pyrheliometer and rotating shadowband irradiometer (RSI) used to measure direct normal irradiance in Golden and Perpignan, respectively.

The second database is derived from measurements realized in Perpignan, at the PROMES-CNRS laboratory. This station is located in Southern France, approximately $20 \mathrm{~km}$ west of the Mediterranean sea. Winter is mild and summer is hot and dry. In addition, there is a lot of wind, often resulting in a cloudless sky. The main characteristics of these two sites are presented in Table II. Note that the DNI measurements have been obtained using different devices: the NREL uses a pyrheliometer, whereas the PROMES-CNRS laboratory uses a rotating shadowband irradiometer (Fig. 1). The typical uncertainties are about $\pm 2 \%$ for the pyrheliometer and $\pm 5 \%$ for the RSI [13]. However, they are clearly higher at both sunrise and sunset, i.e. when DNI is relatively low. Other data like the air mass or solar angles have been directly extracted from the database (NREL) or computed (PROMES-CNRS).

Depending on the location, the dynamics of direct normal irradiance as well as the fluctuations one can observe in 


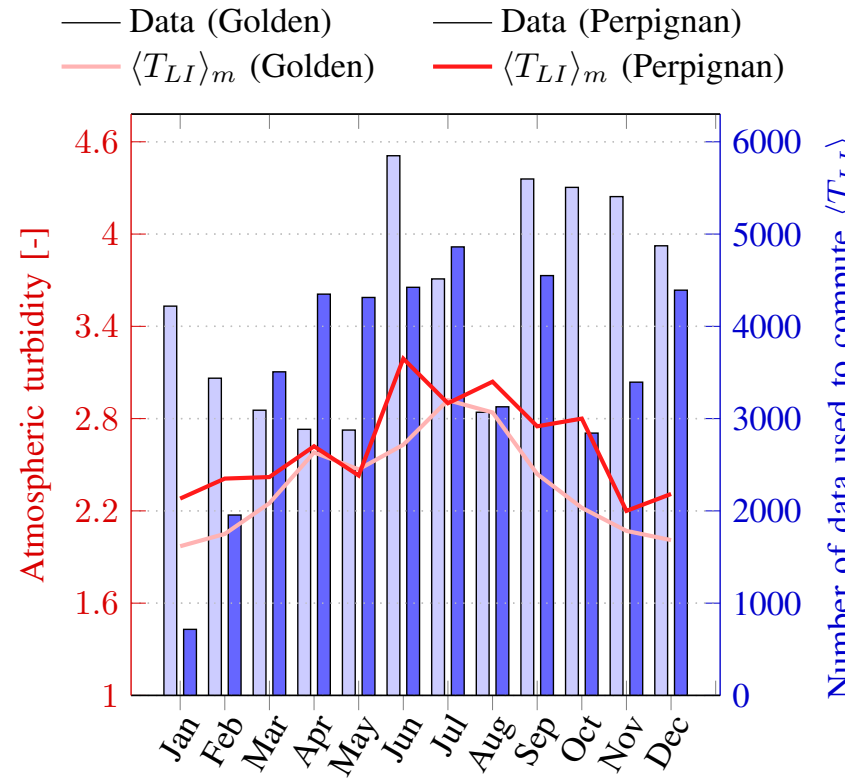

Fig. 2. Monthly mean values of the atmospheric turbidity $\left(\left\langle T_{L I}\right\rangle_{m}\right)$ and number of clear-sky DNI data involved in the computation.

atmospheric turbidity are rather different. During the twelvemonth periods we considered (see Table II), about $850 \mathrm{~h}$ and $700 \mathrm{~h}$ of clear-sky DNI data have been detected in Golden and Perpignan, respectively. Note that, with the exception of January and February in Perpignan, the number of clear-sky DNI data involved in the computation of $T_{L I}$ is higher than 2000, which is enough to obtain representative monthly mean values of atmospheric turbidity (Fig. 2). One can also observe that this quantity is higher in summer than in winter, in both sites. Overall, atmospheric turbidity is higher in Perpignan, probably because of a higher concentration in particles than in Golden (remember that the BMS station elevation is about $1800 \mathrm{~m}$ whereas Perpignan is more or less at sea level).

\section{Methodology FOR THE COMPUTATION OF ATMOSPHERIC TURBIDITY}

\section{A. Principle}

To assess in real time the clear-sky DNI $\left(\hat{I}_{c s 3,5}(t)\right)$, we developed a methodology for the computation of atmospheric turbidity $T_{L I}(t)$. This methodology is mainly based on atmospheric turbidity behaviour and takes advantage of the fact that changes in atmospheric turbidity are relatively small throughout the day in comparison to changes in DNI.

As an example, let us consider that, at a given time $t^{\star}$, we are in a clear-sky situation. Then $I_{c s}\left(t^{\star}\right)=I\left(t^{\star}\right)$ and the last trustable atmospheric turbidity $T_{L I}\left(t^{\star}\right)$ can be computed as follows (Eq. (6)):

$$
T_{L I}\left(t^{\star}\right)=\frac{11.1}{m} \ln \left(\frac{b I_{0}}{I_{c s}\left(t^{\star}\right)}\right)+1
$$

Later, at $t=t^{\star}+\Delta t$, if a new DNI measurement is realized with an unknown situation of the sky, the atmospheric turbidity

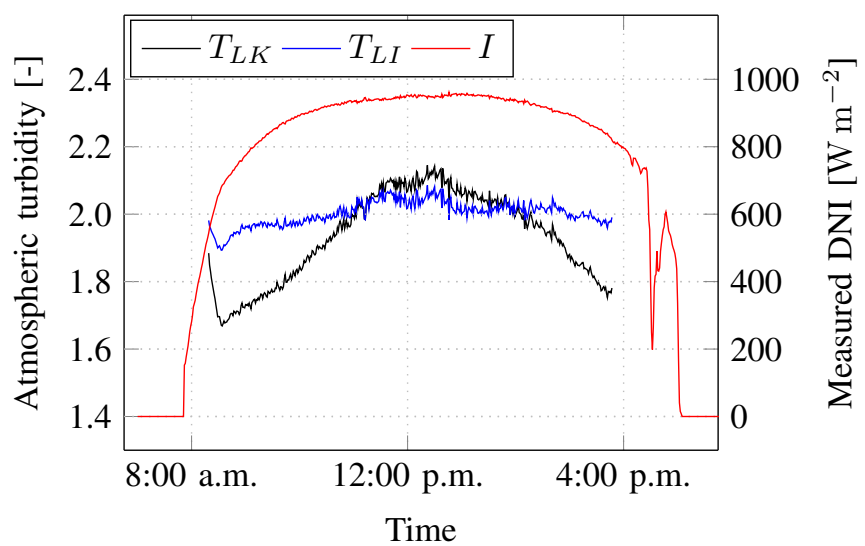

Fig. 3. Evolution of the Kasten modified Linke turbidity coefficient $T_{L K}$ and the Ineichen atmospheric turbidity coefficient $T_{L I}$ during a clear-sky day (from the PROMES-CNRS database).

cannot be deduced. However, a variable $C T_{L I}(t)$ (hereafter called coefficient of turbidity) can be computed using Eq. (7):

$$
C T_{L I}(t)=\frac{11.1}{m} \ln \left(\frac{b I_{0}}{I(t)}\right)+1
$$

Once $C T_{L I}(t)$ is computed, two cases are possible: $C T_{L I}(t) \leqslant T_{L I}\left(t^{\star}\right)$ and $C T_{L I}(t)>T_{L I}\left(t^{\star}\right)$. The first one corresponds to an atmosphere clearest at a given time $t$ than at time $t^{\star}$. As a result, the new situation is also considered as clear sky: $I_{c s}(t)=I(t)$. This deduction is true because, unlike the Kasten modified Linke turbidity expression, the atmospheric turbidity expression given by Ineichen and Perez $\left(T_{L I}\right)$, is air mass independent (Fig. 3).

The second case is more complex because the atmosphere can be polluted during the interval $\Delta t$ (by an increase of aerosol content, for example) but it may still be a clearsky situation. A study based on the speed of the atmosphere opacification is thus required.

\section{B. Opacification speed of the atmosphere}

To determine the sky condition when $C T_{L I}(t)>T_{L I}\left(t^{\star}\right)$, it is necessary to evaluate the maximum possible increase of $T_{L I}$ in the considered site during a given period. This value is computed as follows (Eq. (8)):

$$
v_{L I}^{\star}(t)=\frac{C T_{L I}(t)-T_{L I}\left(t^{\star}\right)}{t-t^{\star}}
$$

The value $v_{L I}^{\star}$ corresponds to the speed at which atmospheric turbidity changes between $t$ and $t^{\star}$. As a result, if the speed $v_{L I}^{\star}$ is inferior to a maximum speed, called $v_{L I}^{\max }$, the corresponding situation is considered as a clear sky (Eq. (9)):

$$
\text { if } \begin{gathered}
v_{L I}^{\star}(t)<v_{L I}^{\max } \\
I_{c s}(t)=I(t)
\end{gathered}
$$

else

$$
I_{c s}(t) \neq I(t)
$$

Note that when a clear-sky situation is detected, $t^{\star}$ is automatically updated and no latency is introduced between 
the DNI acquisition and the decision of the algorithm: the operator knows the situation of the sky in real time. To estimate the maximum opacification speed of the atmosphere, we used a bank of clear-sky data manually collected for the two sites. From these data, it is possible to compute the atmospheric turbidity and to deduce the speed at which atmospheric turbidity changes between two instants $t_{1}$ and $t_{2}$, with $t_{2}>t_{1}$ (Eq. (10)):

$$
v_{L I}\left(t_{1}, t_{2}\right)=\frac{T_{L I}\left(t_{2}\right)-T_{L I}\left(t_{1}\right)}{t_{2}-t_{1}}=\frac{\Delta T_{L I}}{\Delta t}
$$

From all possible couples of $t_{1}$ and $t_{2}$, the maximum opacification speed of the atmosphere can be obtained. Because of the high number of clear-sky data available in both sites, the number of combinations for the $v_{L I}$ computation is very high. As a result, the study focused on couples verifying $t_{2}-t_{1}<10$ days and $T_{L I}\left(t_{2}\right)>T_{L I}\left(t_{1}\right)$. The second condition means that only atmospheric turbidity increases are analysed. Indeed, a decrease of atmospheric turbidity $\left(T_{L I}(t) \leqslant T_{L I}\left(t^{\star}\right)\right)$ directly corresponds to a clear-sky situation.

Now, we have available a database consisting in differences in atmospheric turbidity $\Delta T_{L I}$, with their corresponding time differences $\Delta t$. In order to obtain a representative limit for changes in atmospheric turbidity, the 95th percentile of $\Delta T_{L I}$, called $\Delta T_{L I}^{95}$, has been calculated as a function of $\Delta t$. The results are presented in log-log scale by Fig. 4 .

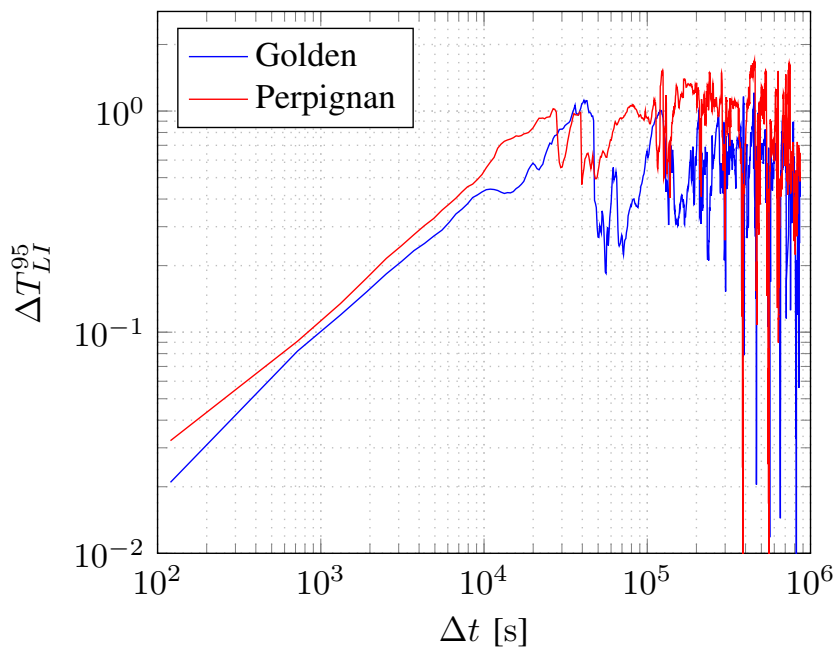

Fig. 4. Evolution of $\Delta T_{L I}^{95}$ as a function of $\Delta t$, in $\log -\log$ scale.

One can observe a good correlation between $\Delta T_{L I}^{95}$ and $\Delta t$, when $\Delta t$ is less than $3 \mathrm{~h}\left(\simeq 10^{4} \mathrm{~s}\right)$. This trend has been obtained taking into account $10^{7}$ couples of atmospheric turbidity values in each experimental site. Statistically, an upper limit for changes at short notice in atmospheric turbidity can be observed. It corresponds to the maximum opacification speed of the atmosphere. However, the correlation between $\Delta T_{L I}^{95}$ and $\Delta t$ is lost when $\Delta t<3 \mathrm{~h}$. Finally, a maximum threshold is reached when $\Delta t$ exceeds an entire day. From these observations, one can define a threshold in order to

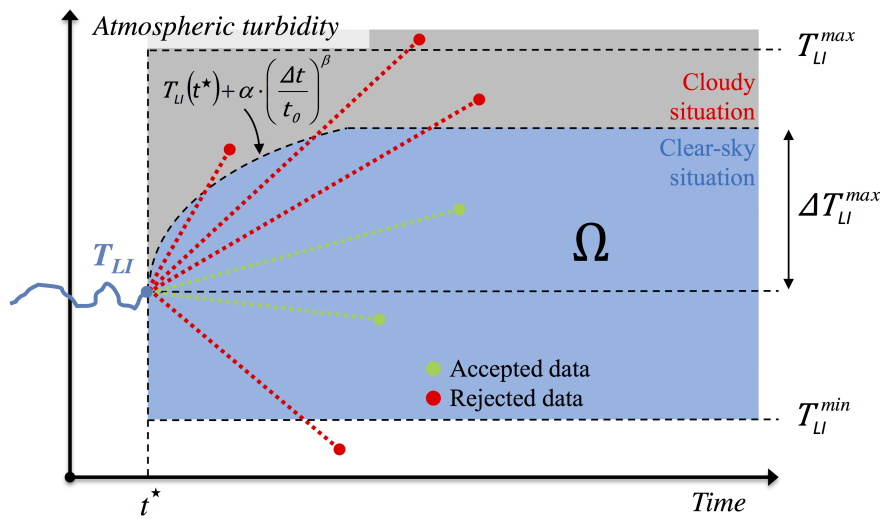

Fig. 5. Methodology for the computation of atmospheric turbidity.

classify atmospheric turbidity increases: they can be caused by modifications in the atmosphere or by the presence of clouds. For $\Delta t$ lower than $3 \mathrm{~h}$, a linear relationship can be observed in log-log scale between $\Delta T_{L I}^{95}$ and $\Delta t$ (Eq. (11)):

$$
\Delta T_{L I}^{95}=\alpha\left(\frac{\Delta t}{t_{0}}\right)^{\beta}
$$

with $t_{0}=1 \mathrm{~s}$. The corresponding maximum value $v_{L I}^{\max }$ can be obtained as follows (Eq. (12)):

$$
v_{L I}^{\max }=\frac{\Delta T_{L I}^{95}}{\Delta t}=\frac{\alpha}{t_{0}}\left(\frac{\Delta t}{t_{0}}\right)^{\beta-1}
$$

When the duration between two clear-sky situations increases, the correlation between $\Delta T_{L I}^{95}$ and $\Delta t$ is reduced. As a result, to avoid considering a high increase in atmospheric turbidity, a threshold $\Delta T_{L I}^{\max }$ has been defined. It corresponds to the maximum acceptable difference between $T_{L I}\left(t^{\star}\right)$ and $C T_{L I}(t)$. All the different thresholds described above are schematically presented in Fig. 5 .

Note that a maximum value $T_{L I}^{\max }$ is added in the computation. It allows the clear-sky situations and cloudy situations to be differentiated, whatever the atmosphere behavior. In addition, a minimum value $T_{L I}^{\min }$ has also been added in the computation in order to avoid cases derived from wrong data acquisitions (e.g. $I>I_{0}$ ). To sum up, a new measurement is related to a clear-sky situation when $C T_{L I}(t) \in \Omega$, with $\Omega$ defined as the blue area on Fig. 5. The different values of the parameters used by the algorithm, for the Golden and Perpignan sites are listed in Table III. Finally, $\hat{I}_{c s}(t)$ is obtained as follows (Eq. (13)):

$$
\begin{array}{ccr}
\text { if } & \text { then } \\
& \hat{I}_{c s}(t)=T_{L s}(t) \in \Omega & \\
\text { else if } & C T_{L I}(t) \notin \Omega \text { and } \Delta t \leqslant 8 \mathrm{~h} & \text { then } \\
& \hat{I}_{c s}(t)=\hat{I}_{c s 3,5}(t) &
\end{array}
$$

else

$$
\hat{I}_{c s}(t)=\hat{I}_{c s 3,4}(t)
$$


TABLE III

VALUES OF THE PARAMETERS USED IN THE CLEAR-SKY DATA DETECTION ALGORITHM.

\begin{tabular}{lll}
\hline Parameter & Golden, USA & Perpignan, France \\
\hline$\alpha$ & $28 \times 10^{-4}$ & $9 \times 10^{-4}$ \\
$\beta$ & 0.6 & 0.75 \\
$\Delta T_{L I}^{\max }$ & 0.5 & 0.6 \\
$T_{L I}^{\max }$ & 5 & 5 \\
$T_{L I}^{\min }$ & 1.5 & 1.8 \\
$t_{0}$ & $1 \mathrm{~s}$ & $1 \mathrm{~s}$ \\
\hline
\end{tabular}

\section{RESULTS AND DISCUSSION}

The accuracy of all the tested approaches has been assessed by means of both the mean absolute error (MAE) and root mean square error (RMSE) (Eqs. (14) and (15)):

$$
\begin{gathered}
M A E_{x y}=\left\langle\left|\hat{I}_{c s x y}-I_{c s}\right|\right\rangle \\
R M S E_{x y}=\sqrt{\left\langle\left(\hat{I}_{c s x y}-I_{c s}\right)^{2}\right\rangle}
\end{gathered}
$$

where $x y$ refers to the notation used in Table $\mathrm{I}, I_{c s}$ corresponds to the measured clear-sky DNI and $\hat{I}_{c s}$ to the estimated value. Table IV summarizes all the results, for the Golden and Perpignan sites. As expected, both the model developed by Ineichen and Perez and the ESRA model work better than the polynomial-based model (even with $N=8$ ), with either monthly or daily mean values of atmospheric turbidity $\left(T_{L I}\right)$ serving as inputs. Indeed, although all the models take the position of the Sun into account, mean turbidity-based models take advantage of an additional information about the state of the atmosphere. One can note that there is no real benefit in considering daily mean values of atmospheric turbidity, instead of monthly mean values, the errors being very close. Moreover, as shown in Figs. 6 and 7, the approach proposed for assessing the clear-sky DNI in real time (i.e. the model developed by Ineichen and Perez combined with a new methodology for the computation of atmospheric turbidity) offers unsurpassed accuracy when the Sun is occulted by clouds during less than eight consecutive hours.

\section{CONCLUSION}

In the present paper, a new approach to the real-time assessement of the clear-sky direct normal irradiance is proposed. It combines an existing empirical model with a new methodology for the computation of atmospheric turbidity. We have decided to use the empirical model developed by Ineichen and Perez in 2002 due to its low dependence on air mass. Indeed, $T_{L I}$ is relatively stable throughout the day. Note that it is also well adapted to real-time applications. The main contribution of the present work lies in the way atmospheric turbidity is computed and updated in real time. We took advantage of the fact that, in case of clear-sky conditions, changes in atmospheric turbidity are relatively small throughout the day in comparison to changes in DNI, even when the sky is free

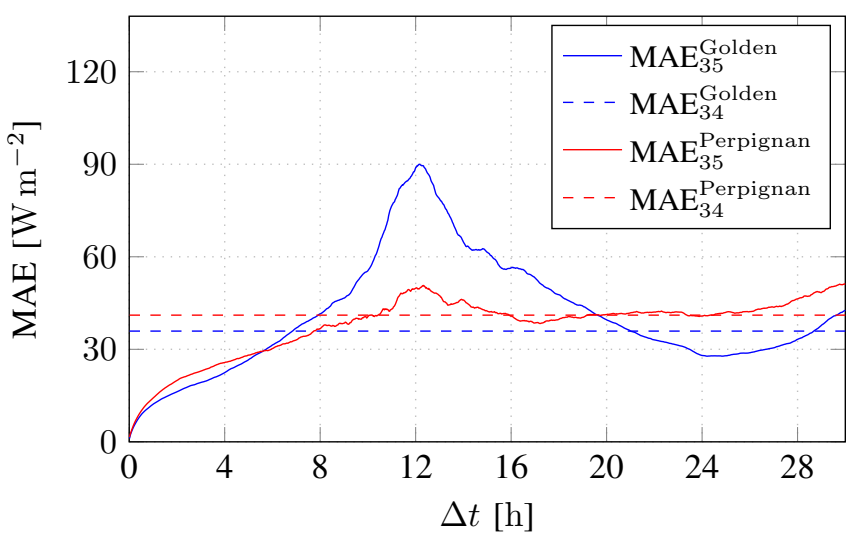

Fig. 6. $\mathrm{MAE}_{3,5}$ as a function of $\Delta t$, for the Golden and Perpignan sites.

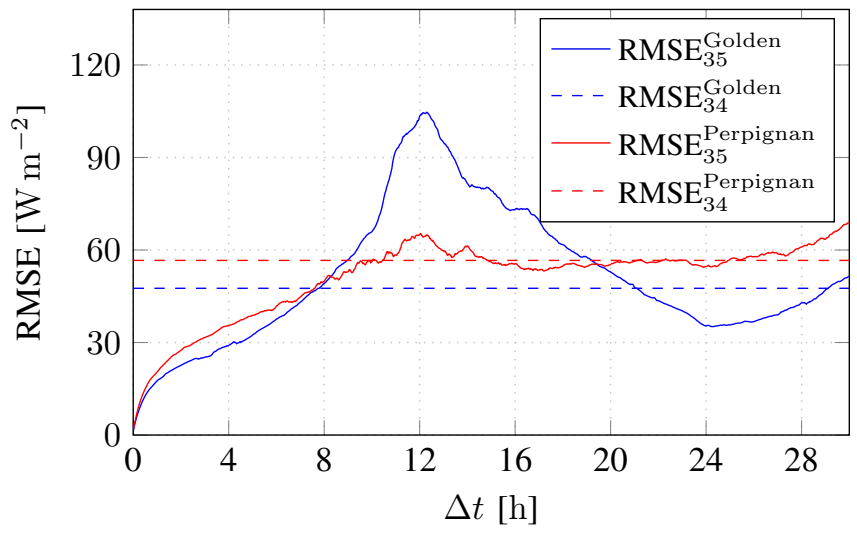

Fig. 7. $\mathrm{RMSE}_{3,5}$ as a function of $\Delta t$, for the Golden and Perpignan sites.

of clouds. So, atmospheric turbidity is computed using the last detected clear-sky DNI measurement.

We have considered data from two experimental sites (Golden, in the USA, and Perpignan, in France), during one entire year, and compared our approach with several combinations of empirical models and ways of computing atmospheric turbidity. Note that the proposed approach offers unsurpassed accuracy when the Sun is occulted by clouds during less than eight consecutive hours. These satisfactory results make it suitable for real-time applications. As a result, it has just been implemented at the $50 \mathrm{MW}$ CSP plant of Palma del Rio II (Palma del Rio, Spain) and will be validated on-site.

\section{REFERENCES}

[1] P. Blanc, B. Espinar, N. Geuder, C. Gueymard, R. Meyer, R. Pitz-Paal, B. Reinhardt, D. Renné, M. Sengupta, L. Wald, and S. Wilbert, "Direct normal irradiance related definitions and applications: The circumsolar issue," Solar Energy, vol. 110, pp. 561-577, 2014.

[2] C. A. Gueymard, "Clear-sky irradiance predictions for solar resource mapping and large-scale applications: Improved validation methodology and detailed performance analysis of 18 broadband radiative models," Solar Energy, vol. 86, no. 8, pp. 2145-2169, 2012.

[3] N. Engerer and F. Mills, "Validating nine clear sky radiation models in Australia," Solar Energy, vol. 120, pp. 9-24, 2015. 
TABLE IV

Comparison of the Considered approaches, FOR Both the Golden AND PERPIGNAN Sites.

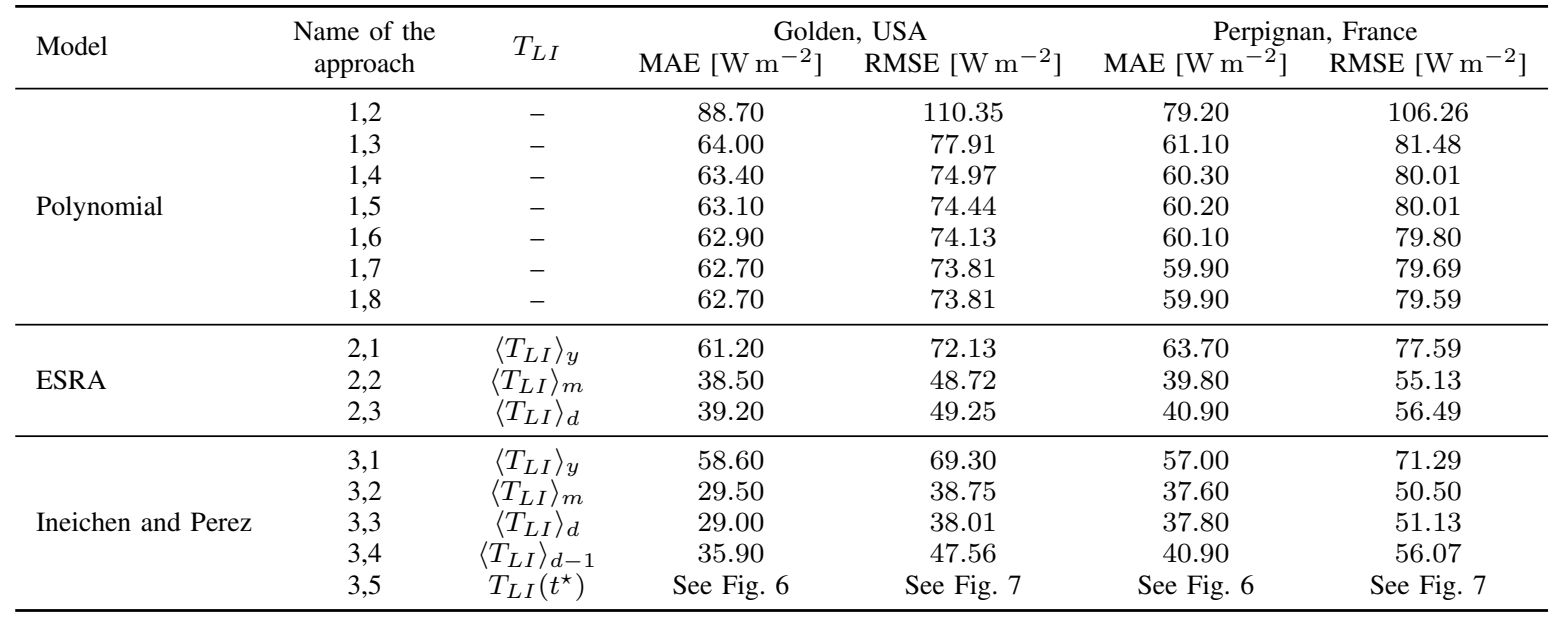

[4] C. A. Gueymard and J. A. Ruiz-Arias, "Validation of direct normal irradiance predictions under arid conditions: A review of radiative models and their turbidity-dependent performance," Renewable and Sustainable Energy Reviews, vol. 45, pp. 379-396, 2015.

[5] Y. Chu, H. T. Pedro, and C. F. Coimbra, "Hybrid intra-hour DNI forecasts with sky image processing enhanced by stochastic learning," Solar Energy, vol. 98, no. C, pp. 592-603, Dec. 2013.

[6] S. Quesada-Ruiz, Y. Chu, J. Tovar-Pescador, H. Pedro, and C. Coimbra, "Cloud-tracking methodology for intra-hour DNI forecasting," Solar Energy, vol. 102, pp. 267-275, 2014.

[7] C. W. Chow, B. Urquhart, M. Lave, A. Dominguez, J. Kleissl, J. Shields, and B. Washom, "Intra-hour forecasting with a total sky imager at the UC san diego solar energy testbed," Solar Energy, vol. 85, no. 11, pp. 2881-2893, 2011.

[8] H. Yang, B. Kurtz, D. Nguyen, B. Urquhart, C. W. Chow, M. Ghonima and J. Kleissl, "Solar irradiance forecasting using a ground-based sky imager developed at UC San Diego," Solar Energy, vol. 103, pp. 502524, May 2014.

[9] Y. Chu, H. T. Pedro, M. Li, and C. F. Coimbra, "Real-time forecasting of solar irradiance ramps with smart image processing," Solar Energy, vol. 114, pp. 91-104, 2015.

[10] P. Ineichen and R. Perez, "A new airmass independent formulation for the Linke turbidity coefficient," Solar Energy, vol. 73, no. 3, pp. 151157, 2002.

[11] SoDa, Solar radiation data, solar energy services for professionals, 2015.

[12] A. Andreas and T. Stoffel, "Baseline measurement system (BMS)," National Renewable Energy Laboratory, Tech. Rep. DA-5500-56488, 1981.

[13] CSP Services, Solar Resource Assessment MDI, mHP - Plant monitoring MHP Meteorological Measurement Systems for CSP Projects, 2015. 